\title{
Prenatal serotonin reuptake inhibitor (SRI) antidepressant exposure and serotonin transporter promoter genotype (SLC6A4) influence executive functions at 6 years of age
}

\section{Whitney M. Weikum ${ }^{1}$, Ursula Brain ${ }^{1}$, Cecil M. Y. Chau ${ }^{1}$, Ruth E. Grunau ${ }^{1}$, W. Thomas Boyce ${ }^{1}$, Adele Diamond ${ }^{2}$ and Tim F. Oberlander ${ }^{1 *}$}

${ }^{1}$ Pediatrics, Child and Family Research Institute, University of British Columbia, Vancouver, BC, Canada

${ }^{2}$ Developmental Cognitive Neuroscience Lab, Psychiatry, University of British Columbia, Vancouver, BC, Canada

\section{Edited by:}

Dirk Schubert, University Medical Center Nijmegen, Netherlands

Reviewed by:

Judith Homberg, Radboud

University Nijmegen Medical

Centre, Netherlands

Jie Zhang, University of Texas

Health Science Center at San

Antonio, USA

\section{*Correspondence}

Tim F. Oberlander, Child and Family Research Institute, F 6054480 Oak Street, Vancouver, BC V6H 3V4,

Canada

e-mail: toberlander@cw.bc.ca
Prenatal exposure to serotonin reuptake inhibitor (SRI) antidepressants and maternal depression may affect prefrontal cognitive skills (executive functions; EFs) including self-control, working memory and cognitive flexibility. We examined long-term effects of prenatal SRI exposure on EFs to determine whether effects are moderated by maternal mood and/or genetic variations in SLC6A4 (a gene that codes for the serotonin transporter [5-HTT] central to the regulation of synaptic serotonin levels and behavior). Children who were exposed to SRIs prenatally (SRI-exposed $N=26)$ and non-exposed $(N=38)$ were studied at age 6 years $(M=6.3 ; S D=0.5)$ using the Hearts \& Flowers task (H\&F) to assess EFs. Maternal mood was measured during pregnancy (3rd trimester) and when the child was age 6 years (Hamilton Depression Scale). Parent reports of child behavior were also obtained (MacArthur Health \& Behavior Questionnaire). Parents of prenatally SRI-exposed children reported fewer child externalizing and inattentive (ADHD) behaviors. Generalized estimate equation modeling showed a significant 3-way interaction between prenatal SRI exposure, SLC6A4 variant, and maternal mood at the 6-year time-point on $\mathrm{H} \& \mathrm{~F}$ accuracy. For prenatally SRI-exposed children, regardless of maternal mood, the H\&F accuracy of children with reduced 5HTT expression (a short [S] allele) remained stable. Even with increasing maternal depressive symptoms (though all below clinical threshold), EFs of children with at least one short allele were comparable to children with the same genotype whose mothers reported few if any depressive symptoms-in this sense they showed resilience. Children with two long $(L)$ alleles were more sensitive to context. When their mothers had few depressive symptoms, LL children showed extremely good EF performance-better than any other group. When their mothers reported more depressive symptoms, LL children's EF performance was worse than that of any other group. In the face of a mother with a more depressed mood, EFs were best preserved in children prenatally exposed to SRIs and with at least one short SLC6A4 allele. Yet, prenatally-exposed LL children hold out promise of possibly superior EF if their mother's mood remains euthymic or improves.

Keywords: serotonin, executive function, childhood, prenatal exposure, SRI, SLC6A4 genotype, depression

\section{INTRODUCTION}

Serotonin (5-HT) and its multiple receptors are highly expressed in prefrontal cortex (PFC) and play key roles in influencing complex cognition and resilience to stress (Canli et al., 2005; Lesch, 2007; Reuter et al., 2007; Homberg and Lesch, 2011). Dense projections of 5-HT neurons into prefrontal regions (Preece et al., 2004), and a wide distribution of 5-HT receptors and 5-HT transporter sites in PFC (Varnäs et al., 2004) contribute to 5-HT's role in cognition (King et al., 2008). Critical cognitive capacities that rely on PFC and related structures (Miller and Cohen, 2001; Braver et al., 2002; Petrides, 2005; Champod and Petrides, 2007; Zanto et al., 2011) are termed executive functions (EFs), and include abilities to (1) focus, sustain and shift attention (executive attention), (2) resist the pulls and temptations of external stimuli, our emotions, or engrained behavioral tendencies, inhibit acting impulsively, taking a moment to make a more considered response (inhibitory control), (3) hold information in mind and work with it, such as updating one's thinking or planning when given new information, considering alternatives, or mentally relating pieces of information to one other (working memory), and (4) creative problem-solving, flexibly adjusting to changed demands, priorities, new obstacles or opportunities (cognitive flexibility; Miyake et al., 2000; Diamond, 2013). Not surprisingly, good EFs are critical for all aspects of life, including mental and physical health and success in school and in life (Moffitt et al., 2011; Diamond, 2013). For example, childhood EFs predict school readiness and success in math and reading throughout all school years from kindergarten through university 
better than does IQ, even when controlling for SES (Bull and Scerif, 2001; Blair, 2002; Riggs et al., 2004; Blair et al., 2005; Gathercole et al., 2005; Blair and Razza, 2007).

5-HT plays a critical role in brain development (Kalueff et al., 2010; Olivier et al., 2011). In animal models, developmental shifts in central 5-HT signaling shape early cognitive capacities setting pathways for learning and behavior later in life (see for review Kalueff et al., 2010). Little, however, is known about how developmental changes in 5-HT influence early cognitive development in humans during childhood.

The increasing use of serotonin reuptake inhibitor (SRI) antidepressants to manage maternal mood disorders during pregnancy (Cooper et al., 2007) raises critical questions about the impact of prenatal altered central 5-HT levels on the development of systems that regulate attention, working memory, and self-control (i.e., EFs) in childhood (Kalueff et al., 2010; Hanley and Oberlander, 2012). SRIs primarily act by blocking reuptake of serotonin transporter protein (5-HTT), thereby increasing how much, and how long, extracellular 5-HT remains active and available. SRIs readily cross the placenta and the blood-brain barrier (Kim et al., 2006) altering fetal central 5-HT levels (Laine et al., 2003). Prenatal SRI exposure affects (1) fetal (Salisbury et al., 2009; Mulder et al., 2011) and newborn neurobehavior (MosesKolko et al., 2005), (2) neonatal stress regulation (Oberlander et al., 2002, 2005), (3) shifts language perception during the first year of life (Weikum et al., 2012), and (4) is associated with emotional regulation in toddlers (Oberlander et al., 2010).

Why some, but not all, children are affected by prenatal SRI exposure is still a central and pressing question (Hanley and Oberlander, 2012). In the early school years prenatally exposed children appear to have typical language development, behavior and IQ (Nulman et al., 2002). However, not all outcomes can be specifically attributed to prenatal antidepressant exposure. Distinguishing the concurrent impact of pre and postnatal maternal mood disturbances remains challenging (Oberlander et al., 2010).

The pre-synaptic membrane-bound serotonin transporter protein (5-HTT) - the very target of SRI antidepressants-is central to the regulation of intra-synaptic 5-HT. Allelic variations in 5-HTTLPR (SLC6A4) influences gene transcription and the amount of 5-HT available at postsynaptic sites (Lesch et al., 1996). The short (S) variant is associated with reduced gene transcription and reduced levels of 5-HTT protein, with an $\sim 50 \%$ reduction in 5-HT reuptake compared to the long (L) variant (Heils et al., 1996; Homberg et al., 2007a). Reduced 5-HTT protein availability and 5-HT reuptake results in a higher effective "serotonin dose."

Homozygosity for the short (S) allele is associated with increased stress sensitivity and risk for emotional disturbances including anxiety and depression but better EFs (not unlike what has been found for the COMT- MET genotype (Goldman et al., 2005; Diamond, 2011). In combination with early life stressors, the short allele has been widely studied as an important risk factor for mental illness later in life (Caspi et al., 2003; Kendler et al., 2005; Lesch, 2007). For example, adolescents who encountered adversity in childhood and are homozygous for the short allele of 5-HTTLPR have a heightened sensitivity to potential negativity and threat in the environment and are more prone to anxiety and depression (Owens et al., 2012). In animal models, increased 5-HT levels secondary to 5-HTT blockade at developmentally sensitive time periods (akin to a human 3rd trimester) causes permanent axonal connection deficits in the somatosensory cortex (Homberg et al., 2010), the lateral geniculate nucleus (Gaspar et al., 2003), and altered neuronal dendritic branching, elongation and pruning (Homberg et al., 2010; Liao and Lee, 2011; Olivier et al., 2011; Simpson et al., 2011; Zheng et al., 2011). Beyond the newborn period, SRI-exposed animals demonstrate decreased 5-HT levels-possibly via prolonged activation of inhibitory receptors (i.e., $5-\mathrm{HT}_{1 \mathrm{a}}$; Hensler, 2006). This might underlie the reduced novelty investigation, poorer motor performance (Lee and Lee, 2012), increased anxiety in conflict tasks and anhedonia (Ansorge et al., 2004, 2008; Popa et al., 2008) reported in fluoxetine-exposed mice. Adults with two short 5-HTTLPR alleles consistently outperform those with one or two long alleles on measures of EFs such as the Wisconsin Card Sorting test (Borg et al., 2009) and go/no-go tests (Roiser et al., 2007), they also show brain patterns consistent with better EFs (Enge et al., 2011). Conversely, the L-allele of the 5-HTTLPR gene is associated with poor EFs including impulsivity, inattention, and working memory deficits (see the meta-analysis by Gizer et al., 2009). Together these findings support the notion that changes in transcriptional activity associated with allelic variations in the 5-HTTLPR gene and presumably reflecting alterations in central serotonin levels, influence EFs in the mature adult brain.

Beyond genetic variations, experimental manipulations of central serotonin levels in adults also appears to affect cognitive functions. Acute SRI administration to healthy adults has been shown to improve verbal fluency, a measure of EFs requiring memory of words, inhibitory control to avoid repeating words, and cognitive flexibility to switch to different paths and strategies for coming up with words (Schmitt et al., 2001). Although reduced 5-HT, using an acute tryptophan depletion (ATD) model with healthy volunteers, has been found to improve focused attention (Schmitt et al., 2000; Evers et al., 2006), enhanced EF performance and reduced impulsivity have also been found in some animal models of SRI exposure (e.g., Sasaki-Adams and Kelley, 2001) but not all (e.g., Valluzzi and Chan, 2007). Importantly, 5-HTTLPR genotype and SRI exposure do not affect, or inconsistently affect, non-EF cognitive abilities such as recall and recognition memory and mental rotation (e.g., 5-HTTLPR genotype: Roiser et al., 2006; Mannie et al., 2009, SRI exposure: Harmer et al., 2002; Siepmann et al., 2003; Riedel et al., 2005).

An acute pharmacological exposure to an SRI or dietary depletion of tryptophan in a mature brain may not result in the same consequences as chronic prenatal SRI exposure and the associated long-term changes in prenatal 5-HT signaling that occurs with such exposure across developmentally sensitive periods of brain growth (Ansorge et al., 2004). To date, studies focusing on the effects of prenatal SRI exposure have typically sought to examine the consequences of what is generally considered increased developmental serotonergic tone. However, in humans the developmental course or behavioral consequences that might follow prenatal SRI exposure (i.e., downstream lower serotonergic tone) is not known. Given the developmental role of 5-HT, it is 
conceivable that prenatal changes in 5-HT either via genetic variations or prenatal SRI exposure might influence early cognitive development in humans.

To further understand the developmental impact of prenatal SRI exposure on early cognitive development, we studied whether prenatal exposure to SRI antidepressants or maternal mood affects core cognitive skills (EFs) in early childhood, controlling for prenatal maternal mood. Secondarily, we also sought to examine whether changes in EFs are moderated by the child's SLC6A4 genotype, reflecting genetic variations in the capacity to control serotonergic tone that may influence the impact of exposure to maternal mood or SRIs. Given fetal changes in 5-HT signaling secondary to prenatal SRI exposure, and the literature showing improved cognitive function among $S$ carriers, we expected that antidepressant exposure and reduced SLC6A4 transcription (at least one short [S] allele) at a developmentally sensitive time (i.e., in utero) would be associated with improved EF capacity in early childhood, while elevated maternal depressive symptoms would have an opposing effect at 6 years of age.

\section{MATERIALS AND METHODS PARTICIPANTS}

Children in this study are part of a longitudinal cohort study examining the effects of prenatal exposure to SRIs and maternal mood disturbances in 98 mothers recruited during their second trimester of pregnancy. Approval was obtained from the University of British Columbia Ethics Board and the Children's and Women's Health Centre of British Columbia Research Review Committee. Written informed parental consent was obtained to follow the development of these children. All mothers, regardless of their mood or medication status, were physicianreferred or self-referred from the Reproductive Mental Health Clinic at British Columbia Women's Hospital and Health Centre (a tertiary-care service), community midwife clinics or family physician practices in the greater Vancouver metropolitan area. All SRI-treated mothers had started taking medications based on clinical need, had a diagnosis of a mood disorder, and were already taking antidepressant medications at the time of conception. Women in the non-SRI group had a range of mood symptoms at the time of recruitment as assessed by the Hamilton Rating Scale for Depression (HAM-D; see Table 1). Of the original 98 mothers, 4 withdrew before the baby was born and another 4 withdrew before the end of the child's first year. At 6 years, an additional 26 children were unavailable for study (22 families had moved and 4 mothers had withdrawn by 3 years). At the time of this study, 64 children (26 prenatally SRI-exposed and 38 nonexposed) were seen at mean age 6.3 years $(S D=0.51$ years). From this sample, 25 exposed and 32 non-exposed had both prenatal maternal mood scores and samples of the child's blood available for genotyping.

\section{CHILD MENTAL HEALTH SYMPTOMATOLOGY}

Measures of child mood and behavior were obtained from the mental health symptomatology section of the MacArthur Health and Behavior Questionnaire (HBQ; Boyce et al., 2002; Essex et al., 2002) that was completed by maternal report (HBQ-P) and yielded measures of internalizing, externalizing and
Table 1 | Maternal characteristics.

\begin{tabular}{|c|c|c|c|c|}
\hline & $\begin{array}{l}\text { Non-exposed } \\
(n=38)\end{array}$ & $\begin{array}{l}\text { SRI-exposed } \\
(n=26)\end{array}$ & $T$ & $p$-value \\
\hline $\begin{array}{l}\text { Prenatal HamA (mean) } \\
(S D)(n=35 \\
\text { non-exposed and } 25 \\
\text { SRI-exposed) }\end{array}$ & $5.5(4.75)$ & $9.58(6.75)$ & -2.8 & 0.007 \\
\hline $\begin{array}{l}\text { Prenatal HamD (mean) } \\
\text { (SD) ( } n=34 \\
\text { non-exposed and } 25 \\
\text { SRI-exposed) }\end{array}$ & $3.64(4.26)$ & $8.54(6.28)$ & -3.66 & 0.001 \\
\hline $\begin{array}{l}\text { Maternal smoking during } \\
\text { pregnancy }\end{array}$ & 0 & 0 & & 0 \\
\hline $\begin{array}{l}\text { Maternal alcohol } \\
\text { consumption (drinks in } \\
\text { pregnancy) }(n=37 \\
\text { non-exposed) }\end{array}$ & $2.49(4.49)$ & $3.69(8.35)$ & -0.74 & 0.462 \\
\hline $\begin{array}{l}\text { Maternal age at birth } \\
\text { (years) }\end{array}$ & $33.21(4.93)$ & $31.42(4.6)$ & 1.45 & 0.151 \\
\hline $\begin{array}{l}\text { Maternal education } \\
\text { (years) }\end{array}$ & $17.8(2.71)$ & $15.27(2.39)$ & 3.83 & 0.001 \\
\hline \multicolumn{5}{|c|}{ MATERNAL SLC6A4 GENOTYPE (n's) } \\
\hline LL & 10 & 7 & & 0.704 \\
\hline $1 S$ & 27 & 18 & & \\
\hline
\end{tabular}

Attention-Deficit and Hyperactivity Disorder (ADHD) behaviors for each child. The HBQ was derived from the Ontario Child Health Study measure designed to map onto DSM-III-R symptom criteria (Boyle et al., 1993). The HBQ-P has strong psychometric properties and has been used to assess child mental health across multiple ages from 4.5 years into adolescence (Ablow et al., 1999; Essex et al., 2006; Shirtcliff and Essex, 2008) The mental health scales have been shown to discriminate groups of children with and without signs of early psychopathology (Luby et al., 2002).

The HBQ-P, administered in questionnaire format, assesses symptoms ranging from "never or not true" to "often or very true." Symptoms in three domains were analyzed: (1) ADHD symptoms consist of items indexing inattention, impulsivity, and hyperactivity. (2) Externalizing symptoms consist of items indexing oppositional defiant behaviors and conduct problems. (3) Internalizing symptoms consist of items indexing symptoms of depression, separation anxiety, and generalized anxiety. In addition to mean symptom level, the percentage of children above clinical cutoffs was examined. Clinical cutoffs for parent reported $\mathrm{ADHD}$, externalizing, and internalizing symptoms $(1.2,0.68,0.71$, respectively) were set based on previous analysis of the HBQ-P (Lemery-Chalfant et al., 2007) with children of approximately the same age as in the present study.

\section{EF TASKS}

EFs were assessed using the H\&F task, a computerized measure that has been validated with children $4-13$ years of age and with adults (Davidson et al., 2006; Diamond et al., 2007). This task assesses inhibition, working memory and cognitive flexibility. A stimulus appears to the right or left of a computer screen 
on every trial. On Block 1 of the task (the congruent block), participants have only to do what comes naturally (i.e., pressing on the same side as the stimulus); no EFs are taxed. On Block 2 (the incongruent block), participants had to resist that prepotent response and instead press on the side opposite the stimulus. On Block 3 (the mixed block), the two types of trials are randomly intermixed, requiring remembering both rules and mentally translating "same [or opposite] side" into "right [or left] hand," and flexibly switching between the two rules, inhibiting one to apply the other.

The children came to the study center mid-morning and first performed a warm up task (about $5 \mathrm{~min}$ ). During the task, children were told to respond to a stimulus as fast as they were able and this gave them practice with the computerized set-up. The children then performed the H\&F task (about $10 \mathrm{~min}$ ). Practice trials were given before both the congruent and incongruent blocks (see Davidson et al., 2006; Diamond et al., 2007). In both blocks, children were given up to $6 \mathrm{~s}$ to respond, and $10 \mathrm{~s}$ in the mixed block. Responses $>2000 \mathrm{~ms}$ were considered incorrect (inattentive) and those $<250 \mathrm{~ms}$, impulsive. Both responses were excluded. Five trials out of 1860 trials were $>2000 \mathrm{~ms}(0.26 \%)$, and there were no trials $<250 \mathrm{~ms}$ (out of 1860 trials in total). Outlier trials were removed by using a lower and upper threshold of 2 standard deviations from the mean RT per trial type per block and per subject.

Two dependent measures were tabulated for each block (i.e., Congruent, Incongruent, etc): (1) correct responses or accuracy $(\%$ correct $=$ \#correct/[\# trials]) and (2) Reaction time or speed of response (reaction time, $\mathrm{RT}>250 \mathrm{msec}$ for correct trials only). Reaction time was a Choice $R T$ tabulated every time a stimulus appeared during the three-block task and the stimulus appeared at random intervals (one button used) (Kail and Salthouse, 1994).

\section{MATERNAL MOOD}

Maternal mood was assessed during the third trimester of pregnancy (mean 33.8 week; SD 1.25 weeks), and again at the 6-year timepoint using the HAM-D; (Hamilton, 1960), a 21item clinician-rated measure of depressive symptoms with a score ranging from 0 to 63 .

\section{SLC6A4 GENOTYPING}

Genomic DNA was extracted from neonatal whole blood samples using the Flexigene DNA Blood Kit (Qiagen, Valencia, California). The $\mathrm{S}$ and $\mathrm{L}$ alleles of SLC6A4 were identified as previously described in (Lesch et al., 1993). Polymerase chain reaction was performed with oligonucleotide primers flanking the polymorphism (corresponding to nucleotide positions -1416 to -1397 [stpr5, 5_- GGCGTTGCCGCTCTGAATGC] and -910 to -888 [stpr3, 5_-GAGGGACTGAGCTGGACAACCAC]) of the 5_-flanking regulatory region of SLC6A4 to generate a 484-bp (S short allele) or a 528-bp (L long allele) polymerase chain reaction product. Polymerase chain reaction amplification was performed in a final volume of $30 \mu \mathrm{L}$ with $50 \mathrm{ng}$ of genomic DNA, 2.5mM deoxyribonucleotides (dGTP/7-deaza-2_$\mathrm{dGTP}=1 / \mathrm{l}), 0.1 \mu \mathrm{g}$ of sense and antisense primers, $10 \mathrm{mM}$ Tris hydrochloride ( $\mathrm{pH} 8.3$ ), $50 \mathrm{mM}$ potassium chloride, $1.5 \mathrm{mM}$ magnesium chloride, and $1 \mathrm{U}$ of Taq DNA polymerase. For quality control, $5 \%$ of the samples were randomly chosen to be retested and their genotypes were consistent with previous results.

\section{STATISTICAL ANALYSES}

Two separate analytic approaches were used to study behavioral outcomes. To analyze child behavioral differences using maternal report, a multivariate analysis of covariance (MANCOVA) was used to examine group (SRI exposed vs. non exposed) differences in child behavior, with child age (at the time of the 6 year study, prenatal (3rd trimester) and postnatal (6 year) maternal mood as covariates. Maternal mood was used as a continuous measure to allow us to account for the wide range of depressive symptoms observed among both SRI-exposed and non-exposed groups. Across time, some mothers in our untreated group became depressed and some crossed over to the SRI treated group. Maternal mood measures at both time points (prenatally and at the 6 year study) helped to account for these changes.

General Estimating Equation (GEE) modeling was used to examine group (SRI exposed vs. non-exposed) and genotype (LL vs. at least one $S$ allele) in relation to each of the three computerized H\&F conditions. Due to a limited number of children with SRI exposure and two short alleles $(n=7)$, children with at least one short allele (LS and SS) were grouped together to yield the $\geq 1 \mathrm{~S}$ allele group. With the GEE approach we were able to examine main effects (SRI exposure and genotype) and interactions simultaneously. The role of genotype was examined as a possible moderator of the effects of prenatal exposure on EFs by comparing performance for each EF task block and interactions between exposure group and SLC6A4 genotype (LL vs. at least one S allele [SS or LS]), accounting for pre- and post-natal maternal mood. GEE extends the generalized linear modeling to allow for analysis of repeated measurement of accuracy (a binomial dependent variable). GEE analyses were performed using SPSS Statistics 18. All $p$-values less than 0.05 were considered significant.

\section{RESULTS}

Demographic and behavioral outcomes for the mothers and their children are presented in Tables $\mathbf{1}, \mathbf{2}$. With the exception of maternal education, maternal mood prenatally and at the 6 year study, child age at the time of the study $(p=0.03)$, and the children's 5-min APGAR scores $(p=0.026)$, no significant group differences (SRI exposed vs. non-exposed) were observed. As SRIexposed children were older than the non-exposed children at the time of the study, child age was included as a covariate in the analyses. While the 5-min APGAR scores were statistically different between groups, the clinical impact of these differences (i.e., between scores of 9.13 vs. 8.73 , Table 1 ) would not reflect a significant difference in outcome and thus were not included in further analyses. We did not include maternal education as a covariate as all mothers had high levels of education.

\section{CHILD MENTAL HEALTH}

In SRI-exposed children, significantly fewer ADHD $(p=0.03)$ and disruptive externalizing symptoms $(p=0.019)$ were reported by parents, after adjusting for child age, 3rd-trimester 
maternal mood and maternal mood at the time of the study. No differences in internalizing behaviors were found between exposure groups (Table 2). Maternal depression symptoms were associated with increased report of externalizing $(r=0.314$; $p=0.01)$ and ADHD behaviors $(r=0.251 ; p=0.039)$. In separate GEE models, internalizing and externalizing behaviors, respectively, were not predictive of EF performance, regardless of concurrent mother's mood.

\section{EF TASK (HEARTS AND FLOWERS)}

To examine the effect of SRI exposure, SLC6A4 variant and maternal mood on EF performance (accuracy and reaction time), a GEE model was run separately on each of the three blocks of the EF task. SRI exposure (yes/no) and SLC6A4 variant (LL vs. at least

\begin{tabular}{|c|c|c|c|c|}
\hline Child characteristics & $\begin{array}{l}\text { Non-exposed } \\
(n=38)\end{array}$ & $\begin{array}{l}\text { SRI-exposed } \\
(n=26)\end{array}$ & $T$ & $p$-value \\
\hline $\begin{array}{l}\text { Gestation age at birth } \\
\text { (mean weeks) }(S D)\end{array}$ & $40.0(1.35)$ & $39.4(1.63)$ & 1.54 & 0.128 \\
\hline Birth weight (grams) (SD) & $3531(470)$ & $3317(480)$ & 1.77 & 0.081 \\
\hline Birth length $(\mathrm{cm})(S D)$ & $51.7(2.8)$ & $50.71(2.54)$ & 1.48 & 0.143 \\
\hline $\begin{array}{l}\text { Head circumference }(\mathrm{cm}) \\
(S D)\end{array}$ & $35.0(1.36)$ & $34.42(1.27)$ & 1.69 & 0.095 \\
\hline Apgars score (1 min) & $8.03(1.6)$ & $7.65(1.55)$ & 0.93 & 0.358 \\
\hline Apgars score (5 min) & $9.13(0.53)$ & $8.73(0.87)$ & 2.28 & 0.026 \\
\hline $\operatorname{Sex}(m: f)$ & $18: 20$ & $10: 16$ & -0.7 & 0.488 \\
\hline SLC6A4 genotype (n's) & & & & 0.946 \\
\hline LL & 11 & 9 & & \\
\hline 1S & 23 & 16 & & \\
\hline Age at study (yr) (SD) & $6.22(0.55)$ & $6.51(0.45)$ & -2.28 & 0.03 \\
\hline $\begin{array}{l}\text { Child mental health } \\
\text { symptomatology }\end{array}$ & & & $\boldsymbol{F}$ & $p$-value \\
\hline $\begin{array}{l}\text { Internalizing symptoms^ } \\
\text { Composite of } \\
\text { depression, separation } \\
\text { anxiety, and generalized } \\
\text { anxiety scores }\end{array}$ & $0.33(0.25)$ & $0.33(0.22)$ & 0.253 & 0.617 \\
\hline $\begin{array}{l}\% \text { above clinical } \\
\text { threshold }\end{array}$ & 6.3 & 8 & & \\
\hline $\begin{array}{l}\text { Externalizing symptoms^ } \\
\text { Composite of } \\
\text { oppositional defiant } \\
\text { behaviors and conduct } \\
\text { problem scores }\end{array}$ & $0.29(0.22)$ & $0.23(0.17)$ & 5.831 & 0.019 \\
\hline $\begin{array}{l}\% \text { above clinical } \\
\text { threshold }\end{array}$ & 6.3 & 0 & & \\
\hline $\begin{array}{l}\text { ADHD Symptoms } \\
\text { Composite of inattention, } \\
\text { impulsivity, and } \\
\text { hyperactivity scores }\end{array}$ & $0.67(0.39)$ & $0.47(0.37)$ & 4.954 & 0.03 \\
\hline $\begin{array}{l}\% \text { above clinical } \\
\text { threshold }\end{array}$ & 9.4 & 0 & & \\
\hline
\end{tabular}

'Controlling for maternal mood (prenatal and 6 year) and child age. one S) were factors. Trials was a repeated within-subject variable, and maternal mood measures (prenatal and at the 6 year study) and child age at test day were covariates. The outcome was either accuracy (\% correct response) or RT (in milliseconds) on the EF task.

\section{REACTION TIME}

Overall, no SRI exposure group differences in RT (Figure 1) were found in any of the 3 blocks. RT increased with increasing task difficulty, but that did not differ by SRI exposure or genotype (LL vs. $\geq 1 \mathrm{~S}$ allele). In a separate analysis of Choice RT task, older children were faster $(B=-35.5, p=0.048)$. To control for speed of responding faster, Choice RT was added to an overall GEE RT model as a covariate. There was still no significant effect for SRI exposure or SLC6A4 genotype (LL vs. $\geq 1 \mathrm{~S}$ allele) in the GEE RT model.

\section{ACCURACY}

Overall, no SRI exposure group differences in accuracy (Figure 2) were found on block 1 or 2 . Differences emerged in the most difficult third block where exposed children showed higher accuracy (suggesting better cognitive flexibility). However, the results were not significant when controlling for child age. Not surprisingly, older children performed better on the EF test $(p=0.004)$; the results of the models were adjusted for child age. Maternal depressed mood at 3rd trimester contributed, but not statistically significantly $(p=0.064, O R=0.943)$.

With each block, differences in accuracy between allelic variations and exposure groups began to emerge, but only in block 3, with accuracy as the dependent variable, a significant main effect for SLC6A4 genotype, child age and maternal mood emerged, as well as a significant 3-way interaction between prenatal SRI exposure, SLC6A4 variant, and maternal mood at age 6 years in the GEE model (Table 3), controlling for child age.

When the mother's current depressed mood symptoms were relatively low (measured on test-day), EF performance did not differ with the presence of prenatal SRI exposure (Figure 2) or by child genotype (Figure 3A, using maternal mood grouped by quartiles to illustrate the GEE results). However, the more depressed the mother was currently, the more performance

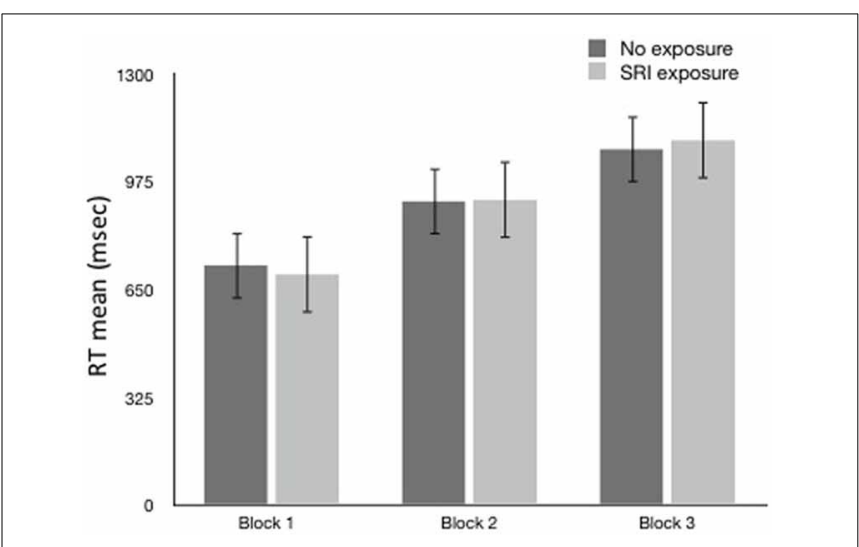

FIGURE 1 | Reaction Time ( $m s \pm$ sem) by block and SRI Exposure. 
between the groups began to diverge. In the face of higher depressive maternal symptoms (4th quartile), EF performance of children with no prenatal SRI exposure was poor. Accuracy was significantly and inversely related to how depressed their mother was currently $\left(B=0.099 ; 95 \%\right.$ CI $[0.035-0.163] ; \chi^{2}=9.295$; $p=0.002)$ and this was particularly true for children with the LL variant $\left(B=-0.092 ; 95 \%\right.$ CI $[-0.171--0.014] ; \chi^{2}=5.29 ; p=$ $0.021)$. Namely, children prenatally exposed to SRIs and with at least $1 \mathrm{~S}$ allele and high concurrent maternal depressive symptoms showed no decrement in accuracy. However, among children with LL variant of SLC6A4, accuracy was worse in children with symptomatic mothers (3rd and 4th quartiles) compared with those with less symptomatic mothers. In contrast, children with $=1$ $S$ allele had relatively stable performance regardless of mothers' depressive mood states (Figure 3B).

\section{DISCUSSION}

On a test of EFs (H\&F; requiring inhibition, working memory, and cognitive flexibility), the effect of prenatal SRI exposure was markedly different in 6-year-old children depending on the child's

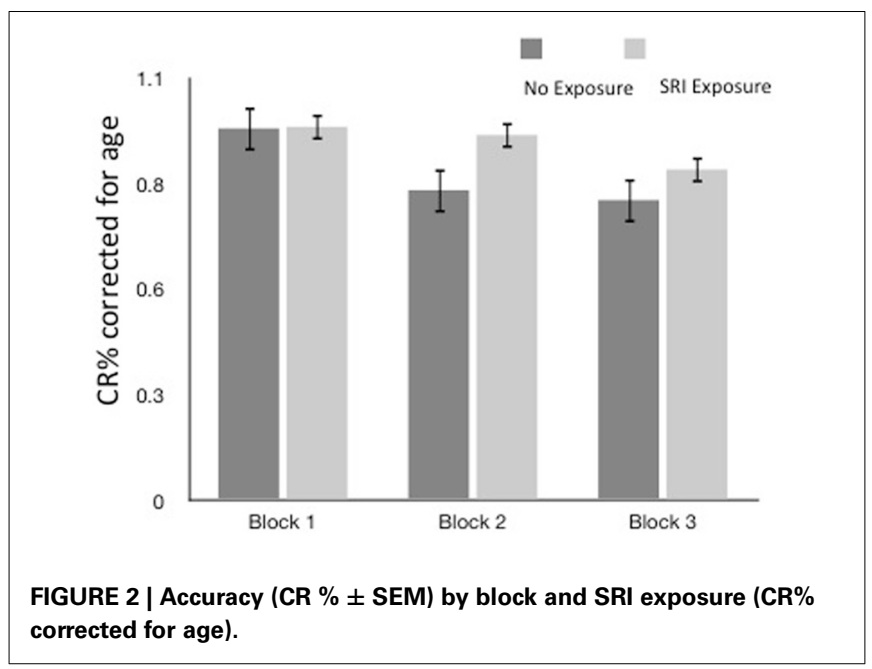

SLC6A4 genotype and mother's concurrent mood. SRI exposed children with an LL genotype showed pronounced differences in their EFs depending on their mother's current mood. SRIexposed children with at least one short SLC6A4 allele showed resilience (no impairment in inhibition and attention). Even in the face of more symptomatic mothers, the accuracy of the $\geq 1 \mathrm{~S}$ children on the difficult mixed Block 3 of the H\&F test did not differ. In contrast, children with two L alleles, were far more sensitive to the context of life with a depressed mother. When their mother had few or no depression symptoms, LL children did

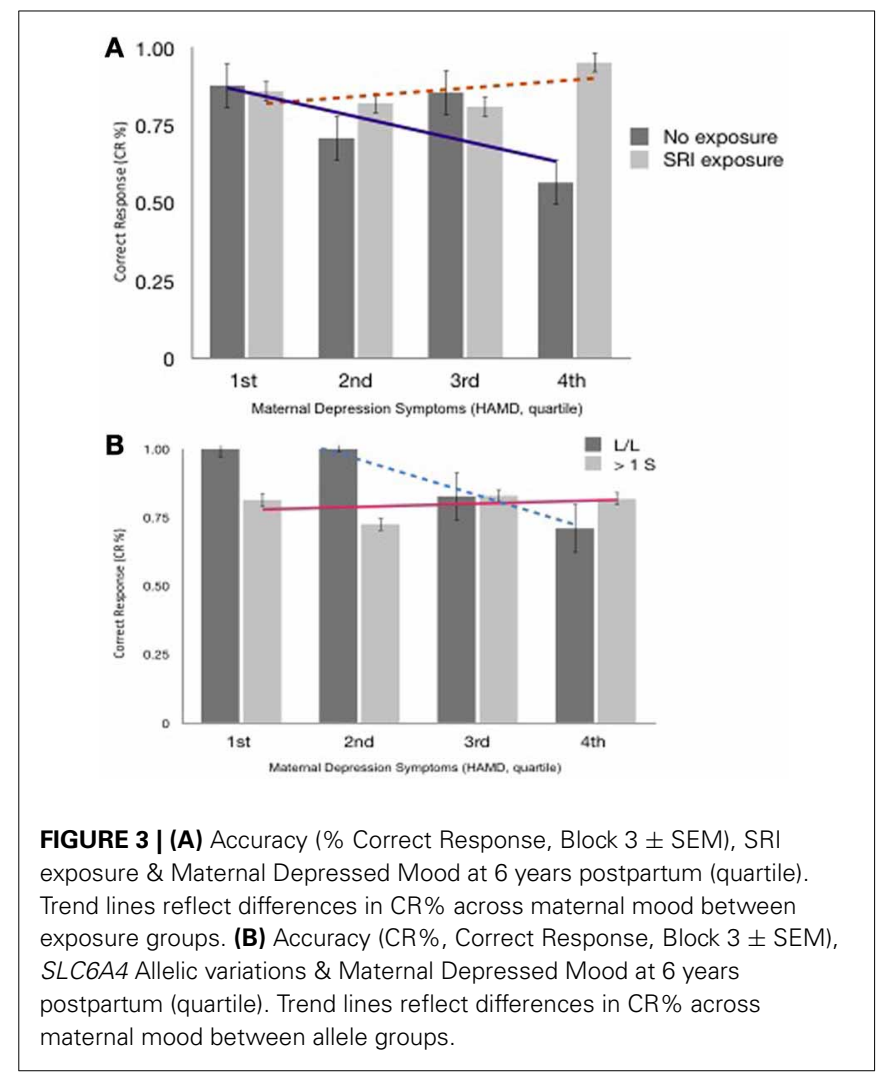

Table 3 | GEE model results (reflecting slope) showing the effect of SRI exposure, SLC6A4 variant, and maternal mood on EF task accuracy.

\begin{tabular}{|c|c|c|c|c|c|}
\hline Parameter & $B^{*}$ & \multicolumn{2}{|c|}{$95 \%$ Wald confidence interval } & Wald $\chi 2$ & $p$-value \\
\hline SLC6A4 LL & 1.051 & 0.263 & 1.838 & 6.838 & 0.009 \\
\hline Third trimester mood (HAMD) & -0.059 & -0.122 & 0.003 & 3.429 & 0.064 \\
\hline Maternal Mood Study Day (HAMD) & 0.099 & 0.035 & 0.163 & 9.295 & 0.002 \\
\hline Prenatal mood * SRI non-exposed * SLC6A4 $\geq 1 \mathrm{~s}$ & 0.056 & -0.024 & 0.136 & 1.884 & 0.17 \\
\hline Prenatal Mood * SRI exposed * SLC6A4 LL & -0.02 & -0.094 & 0.055 & 0.271 & 0.602 \\
\hline Six year maternal mood * SRI non-exposed * SLC6A4 LL & -0.171 & -0.261 & -0.082 & 14.098 & $<0.001$ \\
\hline Six year maternal mood $* S R I$ non-exposed $* S L C 6 A 4 \geq 1 \mathrm{~s}$ & -0.139 & -0.216 & -0.061 & 12.237 & $<0.001$ \\
\hline Six year maternal mood $*$ SRI exposed $*$ SLC6A4 LL & -0.092 & -0.171 & -0.014 & 5.29 & 0.021 \\
\hline
\end{tabular}

$B^{*}$ is the non-standardized regression coefficient. Bold value indicates $p<0.001$. 
extremely well-no other group regardless of SLC6A4 genotype or mother's mood had mean scores that were as high. However, when their mothers were highly symptomatic, they performed worse than any other group including $\geq 1 \mathrm{~S}$ children with equally symptomatic mothers and LL children with less symptomatic mothers.

Differences in accuracy were most evident on the mostdemanding EF Block. In general EF differences between groups often emerge only when cognitive skills are pushed to their limit. Children's EFs were not significantly affected by the child's mood (anxiety or depressive symptoms), though in this cohort there was little variation in the children's subclinical mood symptoms. Parents reported fewer inattentive and externalizing behaviors in children with prenatal SRI exposure regardless of the child's genotype. That might be because the SRI improved the child's postnatal environment (by improving the mother's mood) or because the effect on the 5HT signaling in the child secondary to prenatal SRI exposure. The benefit of one S allele of SLC6A4 to EFs (cognitive control, selfregulation, inhibitory control) in children prenatally exposed to an SRI antidepressant became most apparent when children were in a particular environment (i.e., when their mothers were relatively more depressed). In that environment, the effects of the LL exposed children suffered but the effects of the exposed with $\geq 1 \mathrm{~S}$ allele did not. In this way maternal depression might act as a "prism," dramatically increasing variability in EFs, according to prenatal SRI exposure and allelic variation.

Critical to identifying the impact of prenatal SRI exposure, is distinguishing the effects of the antidepressant from the maternal mood disturbance (pre and postnatal) that resulted in antidepressant medication use. Sensitivity to maternal depressed mood and its impact on cognitive development has been widely reported across childhood (Gelfand and Teti, 1990; Goodman and Gotlib, 1999; Elgar et al., 2004; Gross et al., 2008). Long before birth, early life influences are already shaping core cognitive capacities that go on to become critical for learning and mental health during childhood (Kolb et al., 2003; Fox et al., 2010). Preterm birth (Davis et al., 2011), prenatal psychological distress (Buss et al., 2011) and maternal behavioral risks (smoking, alcohol use, drug use) (Espy et al., 1999; Schonfeld et al., 2006; Blood-Siegfried and Rende, 2010) exert an influence on early EFs. Early and chronic exposure to maternal symptoms adversely affects early development of EFs (Hughes et al., 2013). Yet, not all outcomes on cognitive developmental pathways are necessarily negative in this setting (DiPietro et al., 2006), raising critical questions of how maternal mood affects cognitive development and who remains at risk, even in the presence of maternal pharmacotherapy. In the present study, prenatal SRI exposed children with at least one $\mathrm{S}$ allele showed stable EF functioning regardless of whether their mother was more or less depressed. Moreover, maternal mood in the present study, when their children were 6 years old, was mainly at a subthreshold level, well-below a typical DSM-IV criteria for Major Depressive Diorder (MDD; American Psychiatric Association, 2000), thus highlighting the importance of a spectrum of maternal mood symptoms on child development, rather than a clinical cutoff score.
Converging evidence also points to links between changes in 5-HT signaling and cognition in both animal models and humans (Munafò et al., 2009; Homberg et al., 2010), though not all studies have been consistent (Schmitt et al., 2006; Homberg and Lesch, 2011). Increased 5-HT signaling, secondary to SRI treatment and genetic variations, has been associated with improved cognitive functions. 5-HT transporter knockout rodent models, analogous to an extremely low activity (short allele) variant, have been associated with improved cognitive flexibility during reversal learning tasks (Brigman et al., 2010; Nonkes et al., 2012), as well as morphological frontal cortex changes reflecting an increase in central 5-HT levels (Jedema et al., 2009; Kalueff et al., 2010; Nonkes et al., 2010). Consistent with these findings, early developmental exposure to fluoxetine has been associated with improved spatial learning in rats (Bairy et al., 2006). In humans, carriers of the $S$ allele showed improved performance on an attentional inhibition task (Roiser et al., 2007). Adults homozygous for SS alleles outperform LL carriers on cognitive tasks requiring inhibitory control, including episodic memory and attention (Roiser, 2011), reaction time (Enge et al., 2011) and executive attention (Strobel et al., 2007). Among S carriers, better performance on the Wisconsin Card Sorting test has been reported (Borg et al., 2009), reflecting the impact of increased 5-HT signaling on cognitive flexibility. In contrast, lower 5-HT levels also appear to impair reversal learning (Clarke et al., 2007). Cognitive consequences of increased 5-HT signaling associated with SRI antidepressant exposure have shown mixed results as well. In animal models, not all findings reflect the same impact on cognitive flexibility (Homberg et al., 2007b).

The neuroanatomical, and functional consequences of changing 5-HT levels depend on the timing (critical periods) and direction (increased or decreased) of the developmental exposure to changes in 5-HT signaling and may differ from the impact of an acute exposure in a mature organism. (Ansorge et al., 2007; Kalueff et al., 2010). In a rodent model, SRI exposure during a very specific postnatal period (postnatal days 4-21) of development is also associated, paradoxically, with reduced exploratory behavior, and depressive and anxiety-related behaviors in adulthood. These effects mimic the very effects of genetic 5-HTT inactivation (i.e., gene knockout models leading to the absence of the transporter); suggesting that increased serotonergic signaling during a developmentally critical period predisposes to subsequent affective disturbances (Lira et al., 2003; Ansorge et al., 2004, 2008). This central serotonergic autofeedback hypothesis suggests that increased feedback signaling in the presence of high serotonergic tone blunts maturation of the 5-HT system via long-term developmental activation of inhibitory receptors (i.e., 5- $\mathrm{HT}_{1 \mathrm{a}}$ ), paradoxically leading to psychopathology later in life (Hensler, 2006; Ansorge et al., 2007; Simpson et al., 2011). While one might consider that maternal SRI treatment during pregnancy could potentially confer benefit on fetal neurodevelopment-via improved maternal mood-such exposure could also have detrimental effects later in childhood, reflecting a long-term consequence of decreased serotonergic tone. SRIs may elevate fetal 5-HT levels, but then ultimately lead to decreased 5-HT signaling later in life and restricted serotonergic system development. The serotonergic auto-feedback hypothesis, however, is not a unitary construct and further work 
is needed to understand how developmental changes in 5-HT signaling influences the downstream interaction with the social environment inherent to life with a depressed mother that together contributes to childhood behavior in this setting (Oberlander et al., 2009).

Importantly, not all factors that affect 5-HT signaling confer the same risk. Early life experiential variables influence susceptibility to environmental factors (Moffitt et al., 2005; Caspi and Moffitt, 2006) and not all outcomes associated with the short allele are necessarily negative (Risch et al., 2009). While adults with two short alleles may be at increased risk for depression (Caspi et al., 2003) following early life adversity, those raised in a nurturing environment may ultimately have a lower risk for depressive symptoms (Taylor et al., 2006). Increased central 5-HT associated with the SLC6A4 short allele may therefore contribute to an increased sensitivity to environmental stimuli or hyper vigilance, leading to adaptation in one setting or an increased risk for poor mental health in another. In other words, in a low reward or low adversity setting, such hyper vigilance may confer an actual benefit that increases processing of relevant stimuli improving learning and social cognition (Homberg and Lesch, 2011). In the current study, serotonergic tone, via either prenatal SRI exposure or SLC6A4 allelic variations, appeared to affect a self-regulatory capacity that might heighten sensitivity to a world with a depressed mother. Highly vigilant individuals may therefore either become vulnerable or resilient, depending on the demands of that social environment.

Our findings may also illustrate the influence of how allelic variations in the context of both early (i.e., fetal) and ongoing (i.e., postnatal/childhood) life experience shape a "biological sensitivity to context" (Boyce et al., 1995; Ellis et al., 2011) influencing adaptation and the diversity of child developmental outcomes following early changes in 5-HT signaling. This model proposes that phenotypic plasticity might enable a child to match their biological and behavioral capacities to the demands of their developmental environment. In this context, genetic variations may confer advantages for some children in supportive environments, but disadvantages for others who face social adversity in the context of maternal depression (Boyce and Ellis, 2005). Our findings showing higher accuracy in the non-exposed, LL children in the context of a minimally depressed mother, supports this claim.

Our findings point to a broader understanding of the impact of serotonin developmental neurobiology. While the " $\mathrm{S}$ " allele has been widely considered the "risk" or "sensitive" allele whereby the effect varies with context (Barr et al., 2004; Belsky and Pluess, 2009; Homberg and Lesch, 2011; van Ijzendoorn et al., 2012) our findings suggest that under certain circumstances carriers of the $\mathrm{L}$ allele may also be equally or even more sensitive to context. How this reflects the underlying changes in serotonin signaling (i.e., increased or decreased serotonin at developmentally sensitive times) remains a matter of speculation (Oberlander et al., 2009). Under some circumstances the $\mathrm{L}$ allele may confer vulnerability such as fear in adults exposed to carbon dioxide (Schruers et al., 2011) or aggression in 3-year old children of prenatally anxious mothers (Oberlander et al., 2010) when compared with LS or S allele carriers. Our findings take this observation one step further. Even with similar prenatal exposures, two children with different genetic inheritance show divergent developmental outcomes depending on the environmental circumstances they find themselves in at 6 years of age. Namely, while the impact of allelic variations may be environmentally dependent and the influence can, depending on the childhood context they grow into, go in both directions, thereby reflecting both developmental risk in some settings and resiliency in others. In this way, gene by environment outcomes may reflect a "conditional adaptation" (Boyce and Ellis, 2005) whereby allelic variations can be susceptible to both stressful and supportive contexts-for better and for worse (Belsky et al., 2007).

Conceivably there could be both advantages and disadvantages to improved EF performance. On one hand heightened vigilance may reflect an increased sensitivity in the social world of early childhood. However, it may also reflect a relative deficit in self-regulatory capacity which might illustrate a "leading edge" or susceptibility for a mood disorder that may emerge later in childhood (Taghavi et al., 1999). Interestingly, in a rodent model, an early increase in 5-HT signaling was associated with early fluoxetine exposure and paradoxically leads to increased anxiety and depression behaviors in adulthood (Ansorge et al., 2004). Earlier we reported that increased anxiety and depressive symptoms were observed by parents in 3 year olds with prenatal SRI exposure, though current increased maternal depression symptoms also contributed to child behavior (Oberlander et al., 2010). Now by 6 years of age, in the same cohort, levels of anxious behaviors did not differ between non-exposed children and fewer externalizing and attentional behaviors were observed in the exposed children. The long term implications of this unfolding longitudinal pattern remains unknown, however, improved EFs may reflect an endophenotype that includes increased vigilance that may evolve into a clinically apparent mood disorder in later childhood. Although increased vigilance may confer benefits for short-term tasks in one context (e.g., during a laboratory $\mathrm{EF}$ testing), it may be disadvantageous in the long run under other typical childhood circumstances (e.g., during an entire school day). While improved cognitive control in one setting may confer a developmental advantage (such as life with a depressed mother), the long term consequences of our findings in other childhood contexts (e.g., stressful classroom) need further study.

\section{LIMITATIONS}

A number of limitations need mentioning. First, without direct measures of central changes in 5-HT signaling in utero and again at 6 years, we can only infer that prenatal SRI exposure and genetic variations did indeed alter 5-HT function accounting for our findings. Further, serotonergic system function is dependent on multiple neurochemicals, receptors and related genes, and a focus on prenatal SRI exposure and genetic variations for 5-HT transporters offer only a limited insight into a complex developmental system underlying early human cognitive development. Additionally, study of parent-child relationships which have been noted as key influences on individual differences in a developing child's executive capacities (Carlson, 2003; Hughes and Ensor, 2009; Bernier et al., 2011) are needed. 


\section{SUMMARY}

This study sought to examine the long-term effects of prenatal SRI exposure on EFs at 6 years of age and to determine whether effects are moderated by maternal mood and/or genetic variations. For prenatally SRI-exposed children, regardless of maternal mood, accuracy of children with reduced 5HTT expression (at least one short [S] allele) remained stable regardless of maternal depressive symptoms. In particular, even with somewhat depressed mothers (though all symptoms were below clinical threshold), these children's EFs were comparable to children with the same genotype whose mothers showed few if any depressive symptoms-in this sense, they showed resilience. In contrast, children with two long (L) alleles appeared sensitive to context. When their mothers reported relatively fewer depressed symptoms, LL children showed extremely good EF performance-better than any other group. When mothers reported more depressive symptoms, LL children's EF performance was worse than that of any other group. Further, parents reported fewer inattentive behaviors in their SRI exposed children.

In the face of a mother with a relatively more depressed mood (albeit not at clinical levels), EFs were best preserved in children prenatally exposed to SRIs and with at least one short SLC6A4

\section{REFERENCES}

Ablow, J. C., Measelle, J. R., Kraemer, H. C., Harrington, R., Luby, J., Smider, N., et al. (1999). The macarthur three-city outcome study: evaluating multi-informant measures of young children's symptomatology. J. Am. Acad. Child Adolesc. Psychiatry 38, 1580-1590. doi: 10.1097/00004583-19991200000020

American Psychiatric Association. (2000). Diagnostic and Statistical Manual of Mental Disorders: $D S M-I V-T R^{\circledR}$. Washington, DC: American Psychiatric Pub.

Ansorge, M. S., Hen, R., and Gingrich, J. A. (2007). Neurodevelopmental origins of depressive disorders. Curr. Opin. Pharmacol. 7, 8-17. doi: 10.1016/j.coph.2006.11.006

Ansorge, M. S., Morelli, E., and Gingrich, J. A. (2008). Inhibition of serotonin but not norepinephrine transport during development produces delayed, persistent perturbations of emotional behaviors in mice. J. Neurosci. 28, 199-207. doi: 10.1523/ JNEUROSCI.3973-07.2008

Ansorge, M. S., Zhou, M., Lira, A., Hen, R., and Gingrich, J. A. (2004). Earlylife blockade of the 5-HT transporter alters emotional behavior in adult mice. Science 306, 879-881. doi: 10.1126/science. 1101678

Bairy, K., Madhyastha, S., Ashok, K., Bairy, I., and Malini, S. (2006). Developmental and behavioral consequences of prenatal fluoxetine.
Pharmacology 79, 1-11. doi: 10.1159/000096645

Barr, C. S., Newman, T. K., and Lindell, S., et al. (2004). Interaction between serotonin transporter gene variation and rearingcondition in alcohol preference and consumption in female primates. Arch. Gen. Psychiatry 61, 1146-1152. doi: 10.1001/archpsyc.61.11.1146

Belsky, J., Bakermans-Kranenburg, M. J., and van IJzendoorn, M. H. F. (2007). For better and for worse: differential susceptibility to environmental influences. Curr. Dir. Psychol. Sci. 16, 300-304. doi: 10.1111/j.1467-8721.2007.00525.x

Belsky, J., and Pluess, M. (2009). Beyond diathesis stress: differential susceptibility to environmental influences. Psychol. Bull. 135, 885-908. doi: 10.1037/a0017376

Bernier, A., Carlson, S. M., Deschênes, M., and Matte-Gagné, C. (2011). Social factors in the development of early executive functioning: a closer look at the caregiving environment. Dev. Sci. 15, 12-24. doi: 10.1111/j.1467-7687. 2011.01093. $\mathrm{x}$

Blair, C. (2002). School readiness: Integrating cognition and emotion in a neurobiological conceptualization of children's functioning at school entry. Am. Psychol. 57, 111. doi: 10.1037/0003-066X.57.2.111

Blair, C., Granger, D., and Peters Razza, R. (2005). Cortisol reactivity is positively related to executive function in preschool children

allele. Yet, prenatally-exposed LL children hold out promise of possibly superior EF if their mother's mood remains euthymic or improves. Together these findings may reflect effects of both increased and decreased early serotonergic signaling associated with an increased sensitivity to social and relational contexts. While improved EFs might reflect an apparent resiliency to an "at risk" social environment, the long term and clinical implications of these findings remain to be determined.

\section{ACKNOWLEDGMENTS}

We thank the mothers and their children who participated and contributed to this work. We are grateful to Joannie Maynard and Deborah Heard for their assistance with data collection. This research was funded by March of Dimes Foundation (USA), the Child and Family Research Institute (UBC) and the Canadian Institutes of Health Research [Tim F. Oberlander (PI), CIHR \#MOP 57837] and 6 year grant (MOP-86296). Tim F. Oberlander is the R. Howard Webster Professor in Brain Imaging and Early Child Development (UBC). Whitney M. Weikum was supported by postdoctoral fellowships from CIHR, Michael Smith Foundation for Health Research and funding from the Sunny Hill Foundation. Funding sources had no role in the study.

attending Head Start. Child Dev. 76, 554-567. doi: $10.1111 / \mathrm{j} .1467$ 8624.2005.00863.x

Blair, C., and Razza, R. P. (2007). Relating effortful control, executive function, and false belief understanding to emerging math and literacy ability in kindergarten. Child Dev. 78, 647-663. doi: 10.1111/j.1467-8624.2007.01019.x

Blood-Siegfried, J., and Rende, E. K. (2010). The long-term effects of prenatal nicotine exposure on neurologic development. J. Midwifery Womens Health 55, 143-152. doi: 10.1016/j.jmwh.2009.05.006

Borg, J., Henningsson, S., Saijo, T., Inoue, M., Bah, J., Westberg, L., et al. (2009). Serotonin transporter genotype is associated with cognitive performance but not regional 5-HT1A receptor binding in humans. Int. J. Neuropsychopharmacol. 12, 783-792. doi: 10.1017/ S1461145708009759

Boyce, W. T., Chesney, M., Alkon, A., Tschann, J. M., Adams, S., Chesterman, B., et al. (1995). Psychobiologic reactivity to stress and childhood respiratory illnesses: results of two prospective studies. Psychosom. Med. 57, 411-422.

Boyce, W. T., and Ellis, B. J. (2005). Biological sensitivity to context: I. An evolutionary-developmental theory of the origins and functions of stress reactivity. Dev. Psychopathol. 17, 271-301. doi: 10.1017/S0954579405050145
Boyce, W. T., Essex, M. J., Woodward, H. R., Measelle, J. R., Ablow, J. C., and Kupfer, D. J. (2002). The confluence of mental, physical, social, and academic difficulties in middle childhood. I: exploring the "headwaters" of early life morbidities. J. Am. Acad. Child Adolesc. Psychiatry 41, 580-587. doi: 10.1097/00004583-20020500000016

Boyle, M. H., Offord, D. R., Racine, Y., Fleming, J. E., Szatmari, P., and Sanford, M. (1993). Evaluation of the revised Ontario child health study scales. J. Child Psychol. Psychiatry 34, 189-213. doi: 10.1111/j.14697610.1993.tb00979.x

Braver, T. S., Cohen, J. D., and Barch, D. M. (2002). "The role of the prefrontal cortex in normal and disordered cognitive control: a cognitive neuroscience perspective," in Principles of Frontal Lobe Function, eds D. T. Stuss and R. T. Knight (Oxford, England: Oxford University Press), 428-448.

Brigman, J. L., Mathur, P., HarveyWhite, J., Izquierdo, A., Saksida, L. M., Bussey, T. J., et al. (2010). Pharmacological or genetic inactivation of the serotonin transporter improves reversal learning in mice. Cereb. Cortex 20, 1955-1963. doi: 10.1093/cercor/bhp266

Bull, R., and Scerif, G. (2001). Executive functioning as a predictor of children's mathematics ability: Inhibition, switching, 
and working memory. Dev. Neuropsychol. 19, 273-293. doi: 10.1207/S15326942DN1903_3

Buss, C., Davis, E., Hobel, C., and Sandman, C. (2011). Maternal pregnancy-specific anxiety is associated with child executive function at 6-9 years age. Stress 14, 665-676.

Canli, T., Omura, K., Haas, B. W., Fallgatter, A., Constable, R. T., and Lesch, K. P. (2005). Beyond affect: a role for genetic variation of the serotonin transporter in neural activation during a cognitive attention task. Proc. Natl. Acad. Sci. U.S.A. 102, 12224-12229. doi: $10.1073 /$ pnas.0503880102

Carlson, S. M. (2003). Executive function in context: development, measurement, theory, and experience. Monogr. Soc. Res. Child Dev. 68, 138-151. doi: 10.1111/j.15405834.2003.06803012.x

Caspi, A., and Moffitt, T. E. (2006). Gene-environment interactions in psychiatry: joining forces with neuroscience. Nat. Rev. Neurosci. 7, 583-590. doi: 10.1038/nrn1925

Caspi, A., Sugden, K., Moffitt, T. E., Taylor, A., Craig, I. W., Harrington, H., et al. (2003). Influence of life stress on depression: moderation by a polymorphism in the 5 -HTT gene. Science 301, 386-389. doi: 10.1126/science. 1083968

Champod, A. S., and Petrides, M. (2007). Dissociable roles of the posterior parietal and the prefrontal cortex in manipulation and monitoring processes. Proc. Natl. Acad. Sci. U.S.A. 104, 14837-14842. doi: 10.1073/pnas.0607101104

Clarke, H., Walker, S., Dalley, J., Robbins, T., and Roberts, A. (2007). Cognitive inflexibility after prefrontal serotonin depletion is behaviorally and neurochemically specific. Cereb. Cortex 17, 18-27. doi: 10.1093/cercor/bhj120

Cooper, W. O., Willy, M. E., Pont, S. J., and Ray, W. A. (2007). Increasing use of antidepressants in pregnancy. Am. J. Obstet. Gynecol. 196, 544.e1-544.e5. doi: 10.1016/j.ajog.2007.01.033

Davidson, M. C., Amso, D., Anderson, L. C., and Diamond, A. (2006). Development of cognitive control and executive functions from 4 to 13 years: evidence from manipulations of memory, inhibition, and task switching. Neuropsychologia 44, 2037. doi: $10.1016 /$ j.neuropsychologia. 2006.02.006

Davis, E. P., Buss, C., Muftuler, L. T., Head, K., Hasso, A., Wing, D. A., et al. (2011). Children's brain development benefits from longer gestation. Front. Psychol. 2, 1-7. doi: 10.3389/fpsyg.2011.00001

Diamond, A. (2011). Biological and social influences on cognitive control processes dependent on prefrontal cortex. Prog. Brain Res. 189, 319-339. doi: 10.1016/B978-0-44453884-0.00032-4

Diamond, A. (2013). Executive Functions. Annu. Rev. Psychol. 64, 135-168. doi: 10.1146/annurevpsych-113011-143750

Diamond, A., Barnett, W. S., Thomas, J., and Munro, S. (2007). Preschool program improves cognitive control. Science 318, 1387-1388. doi: 10.1126/science. 1151148

DiPietro, J. A., Novak, M. F. S. X., Costigan, K. A., Atella, L. D., and Reusing, S. P. (2006). Maternal psychological distress during pregnancy in relation to child development at age two. Child Dev. 77, 573-587. doi: 10.1111/j.14678624.2006.00891.x

Elgar, F. J., McGrath, P. J., Waschbusch, D. A., Stewart, S. H., and Curtis, L. J. (2004). Mutual influences on maternal depression and child adjustment problems. Clin. Psychol. Rev. 24, 441-459. doi: 10.1016/j.cpr.2004.02.002

Ellis, B. J., Boyce, W. T., Belsky, J., and Bakermans-Kranenburg, $M$. J. (2011). Differential susceptibility to the environment: an evolutionary-neurodevelopmental theory. Dev. Psychopathol. 23, 7. doi: 10.1017/S0954579410000611

Enge, S., Fleischhauer, M., Lesch, K. P., Reif, A., and Strobel, A. (2011). Serotonergic modulation in executive functioning: linking genetic variations to working memory performance. Neuropsychologia 49, 3776-3785. doi: 10.1016/j. neuropsychologia.2011.09.038

Espy, K. A., Kaufmann, P. M., and Glisky, M. L. (1999). Neuropsychologic function in toddlers exposed to cocaine in utero: a preliminary study. Dev. Neuropsychol. 15, 447-460. doi: 10.1080/87565649909540761

Essex, M. J., Boyce, W. T., Goldstein, L. H., Armstrong, J. M., Kraemer, H. C., and Kupfer, D. J. (2002). The confluence of mental, physical, social, and academic difficulties in middle childhood. II: developing the macarthur health and behavior questionnaire. J. Am. Acad. Child Adolesc. Psychiatry 41, 588-603. doi: 10.1097/00004583-20020500000017

Essex, M. J., Kraemer, H. C., Armstrong, J. M., Boyce, W. T., Goldsmith, H. H., Klein, M. H., et al. (2006). Exploring risk factors for the emergence of children's mental health problems. Arch. Gen. Psychiatry 63, 1246-1256. doi: 10.1001/archpsyc.63.11.1246

Evers, E., Van der Veen, F., Jolles, J., Deutz, N., and Schmitt, J. (2006). Acute tryptophan depletion improves performance and modulates the BOLD response during a Stroop task in healthy females. Neuroimage 32, 248-255. doi: 10.1016/j.neuroimage.2006.03.026

Fox, S. E., Levitt, P., and Nelson, C. A. (2010). How the timing and quality of early experiences influence the development of brain architecture. Child Dev. 81, 28-40. doi: 10.1111/j.1467-8624.2009.01380.x

Gaspar, P., Cases, O., and Maroteaux, L. (2003). The developmental role of serotonin: news from mouse molecular genetics. Nat. Rev. Neurosci. 4, 1002-1012. doi: 10.1038/nrn1256

Gathercole, S. E., Tiffany, C., Briscoe, J., and Thorn, A. (2005). Developmental consequences of poor phonological short-term memory function in childhood: a longitudinal study. J. Child Psychol. Psychiatry 46, 598-611. doi: 10.1111/j.1469-7610.2004.00379.x

Gelfand, D. M., and Teti, D. M. (1990). The effects of maternal depression on children. Clin. Psychol. Rev. 10, 329-353. doi: 10.1016/02727358(90)90065-I

Gizer, I. R., Ficks, C., and Waldman, I. D. (2009). Candidate gene studies of ADHD: a meta-analytic review. Hum. Genet. 126, 51-90. doi: 10.1007/s00439-009-0694-x

Goldman, D., Oroszi, G., and Ducci, F. (2005). The genetics of addictions: uncovering the genes. Nat. Rev. Genet. 6, 521-532. doi: $10.1038 / \mathrm{nrg} 1635$

Goodman, S. H., and Gotlib, I. H. (1999). Risk for psychopathology in the children of depressed mothers: a developmental model for understanding mechanisms of transmission. Psychol. Rev. 106, 458. doi: 10.1037/0033-295X.106.3.458

Gross, H. E., Shaw, D. S., Moilanen, K. L., Dishion, T. J., and Wilson, M. N. (2008). Reciprocal models of child behavior and depressive symptoms in mothers and fathers in a sample of children at risk for early conduct problems. J. Fam. 22, 742. doi: 10.1037/a0013514

Hamilton, M. (1960). A rating scale for depression. J. Neurol. Neurosurg. Psychiatr. 23, 56-62. doi: 10.1136/jnnp.23.1.56

Hanley, G. E., and Oberlander, T. F. (2012). Neurodevelopmental outcomes following prenatal exposure to serotonin reuptake inhibitor antidepressants: a "social teratogen" or moderator of developmental risk? Birth Defects Res. A 94, 651-659. doi: 10.1002/bdra.23032

Harmer, C. J., Bhagwagar, Z., Cowen, P. J., and Goodwin, G. M. (2002). Acute administration of citalopram facilitates memory consolidation in healthy volunteers. Psychopharmacology 163, 106-110. doi: 10.1007/s00213-002-1151-x

Heils, A., Teufel, A., Petri, S., Stöber, G., Riederer, P., Bengel, D. et al. (1996). Allelic variation of human serotonin transporter gene expression. J. Neurochem. 66 , 2621-2624. doi: 10.1046/j.14714159.1996.66062621.x

Hensler, J. G. (2006). Serotonergic modulation of the limbic system. Neurosci. Biobehav. Rev. 30 203-214. doi: 10.1016/j.neubiorev. 2005.06.007

Homberg, J. R., and Lesch, K. P. (2011). Looking on the bright side of serotonin transporter gene variation. Biol. Psychiatry 69, 513-519. doi: 10.1016/j.biopsych.2010.09.024

Homberg, J., Olivier, J., Smits, B., Mul, J., Mudde, J., Verheul, M., et al. (2007a). Characterization of the serotonin transporter knockout rat: a selective change in the functioning of the serotonergic system. Neuroscience 146, 1662-1676. doi: 10.1016/j.neuroscience.2007.03.030

Homberg, J. R., Pattij, T., Janssen, M. C., Ronken, E., De Boer, S. F., Schoffelmeer, A. N., et al. (2007b). Serotonin transporter deficiency in rats improves inhibitory control but not behavioural flexibility. Eur. J. Neurosci. 26, 2066-2073. doi: 10.1111/j.1460-9568.2007.05839.x

Homberg, J. R., Schubert, D., and Gaspar, P. (2010). New perspectives on the neurodevelopmental effects of SSRIs. Trends Pharmacol. Sci. 31, 60-65. doi: 10.1016/j.tips.2009.11.003

Hughes, C., Roman, G., Hart, M. J., and Ensor, R. (2013). Does maternal depression predict young children's executive function?-a 4year longitudinal study. J. Child Psychol. Psychiatry 54, 169-177. doi: 10.1111/jcpp.12014

Hughes, C. H., and Ensor, R. A. (2009) How do families help or hinder the emergence of early executive function? New Dir. Child Adolesc. Dev. 2009, 35-50. doi: 10.1002/cd.234

Jedema, H. P., Gianaros, P. J., Greer, P. J., Kerr, D. D., Liu, S., Higley, J. D., et al. (2009). Cognitive impact of genetic variation of the serotonin transporter in primates is associated with differences in brain morphology rather than 
serotonin neurotransmission. Mol. Psychiatry 15, 512-522. doi: 10.1038/mp.2009.90

Kail, R., and Salthouse, T. A. (1994). Processing speed as a mental capacity. Acta Psychol. 86, 199-225. doi: 10.1016/0001-6918(94)90003-5

Kalueff, A., Olivier, J., Nonkes, L., and Homberg, J. (2010). Conserved role for the serotonin transporter gene in rat and mouse neurobehavioral endophenotypes. Neurosci. Biobehav. Rev. 34, 373-386. doi: 10.1016/j.neubiorev.2009.08.003

Kendler, K. S., Kuhn, J. W., Vittum, J., Prescott, C. A., and Riley, B. (2005). The interaction of stressful life events and a serotonin transporter polymorphism in the prediction of episodes of major depression: a replication. Arch. Gen. Psychiatry 62, 529-535. doi: 10.1001/archpsyc.62.5.529

Kim, J., Riggs, K. W., Misri, S., Kent, N., Oberlander, T. F., Grunau, R. E., et al. (2006). Stereoselective disposition of fluoxetine and norfluoxetine during pregnancy and breastfeeding. Br. J. Clin. Pharmacol. 61, 155-163. doi: 10.1111/j.13652125.2005.02538.x

King, M. V., Marsden, C. A., and Fone, K. C. (2008). A role for the 5HT1A, 5-HT 4 and 5-HT6 receptors in learning and memory. Trends Pharmacol. Sci. 29, 482-492. doi: 10.1016/j.tips.2008.07.001

Kolb, B., Gibb, R., and Robinson, T. E. (2003). Brain plasticity and behavior. Curr. Dir. Psychol. 12, 1-5. doi: 10.1111/1467-8721.01210

Laine, K., Heikkinen, T., Ekblad, U., and Kero, P. (2003). Effects of exposure to selective serotonin reuptake inhibitors during pregnancy on serotonergic symptoms in newborns and cord blood monoamine and prolactin concentrations. Arch. Gen. Psychiatry 60, 720-726. doi: 10.1001/archpsyc.60.7.720

Lee, L., and Lee, L. J. (2012). Neonatal fluoxetine exposure alters motor performances of adolescent rats. Dev. Neurobiol. 72, 1122-1132. doi: 10.1002/dneu.20942

Lemery-Chalfant, K., Schreiber, J. E., Schmidt, N. L., Van Hulle, C. A., Essex, M. J., and Goldsmith, H. (2007). Assessing internalizing, externalizing, and attention problems in young children: validation of the MacArthur HBQ. J. Am. Acad. Child Adolesc. Psychiatry 46, 1315-1323. doi: 10.1097/chi.0b013e3180f616c6

Lesch, K. (2007). Linking emotion to the social brain. EMBO Rep. 8, S24-S29. doi: 10.1038/sj.embor.7401008
Lesch, K., Bengel, D., Heils, A., Sabol, S. Z., Greenberg, B. D. Petri, S., et al. (1996). Association of anxiety-related traits with a polymorphism in the serotonin transporter gene regulatory region. Science 274, 1527-1531. doi: 10.1126/science.274.5292.1527

Lesch, K., Wolozin, B., Estler, H., Murphy, D., and Riederer, P. (1993). Isolation of a cDNA encoding the human brain serotonin transporter. J. Neural Transm. 91, 67-72. doi: 10.1007/BF01244919

Liao, C., and Lee, L. (2011). Neonatal fluoxetine exposure affects the action potential properties and dendritic development in cortical subplate neurons of rats. Toxicol. Lett. 207, 314-321. doi: 10.1016/j.toxlet.2011.09.028

Lira, A., Zhou, M., Castanon, N., Ansorge, M. S., Gordon, J. A., Francis, J. H., et al. (2003). Altered depression-related behaviors and functional changes in the dorsal raphe nucleus of serotonin transporter-deficient mice. Biol. Psychiatry 54, 960-971. doi: 10.1016/S0006-3223(03)00696-6

Luby, J. L., Heffelfinger, A., Measelle, J. R., Ablow, J. C., Essex, M. J., Dierker, L., et al. (2002). Differential performance of the MacArthur HBQ and DISC-IV in identifying DSMIV internalizing psychopathology in young children. J. Am. Acad. Child Adolesc. Psychiatry 41, 458-466. doi: 10.1097/00004583-20020400000019

Mannie, Z., Barnes, J., Bristow, G., Harmer, C., and Cowen, P. (2009). Memory impairment in young women at increased risk of depression: influence of cortisol and 5-HTT genotype. Psychol. Med. 39, 757-762. doi: 10.1017/S0033291708004248

Miller, E. K., and Cohen, J. D. (2001). An integrative theory of prefrontal cortex function. Аnnu. Rev. Neurosci. 24, 167-202. doi: 10.1146/annurev.neuro.24.1.167

Miyake, A., Friedman, N. P., Emerson, M. J., Witzki, A. H., Howerter, A., and Wager, T. D. (2000). The unity and diversity of executive functions and their contributions to complex "frontal lobe" tasks: a latent variable analysis. Cognit. Psychol. 41, 49-100. doi: 10.1006/cogp.1999.0734

Moffitt, T. E., Arseneault, L., Belsky, D., Dickson, N., Hancox, R. J., Harrington, H., et al. (2011). A gradient of childhood selfcontrol predicts health, wealth, and public safety. Proc. Natl. Acad. Sci. U.S.A. 108, 2693-2698. doi: $10.1073 /$ pnas. 1010076108
Moffitt, T. E., Caspi, A., and Rutter, M. (2005). Strategy for investigating interactions between measured genes and measured environments. Arch. Gen. Psychiatry 62, 473-481. doi: 10.1001/archpsyc.62.5.473

Moses-Kolko, E. L., Bogen, D., Perel, J., Bregar, A., Uhl, K., Levin, B., et al. (2005). Neonatal signs after late in utero exposure to serotonin reuptake inhibitors. J. Am. Med. Assoc. 293, 2372-2383. doi: 10.1001/jama.293.19.2372

Mulder, E. J., Ververs, F. F., de Heus, R., and Visser, G. H. (2011). Selective serotonin reuptake inhibitors affect neurobehavioral development in the human fetus. Neuropsychopharmacology 36, 1961-1971. doi: 10.1038/npp. 2011.67

Munafò, M. R., Durrant, C., Lewis, G., and Flint, J. (2009). Genex environment interactions at the serotonin transporter locus. Biol. Psychiatry 65, 211-219. doi: 10.1016/j.biopsych.2008.06.009

Nonkes, L. J., Tomson, K., Mærtin, A., Dederen, J., Roald Maes, J., and Homberg, J. (2010). Orbitofrontal cortex and amygdalar over-activity is associated with an inability to use the value of expected outcomes to guide behaviour in serotonin transporter knockout rats. Neurobiol. Learn. Mem. 94, 65-72. doi: 10.1016/j.nlm.2010. 04.002

Nonkes, L. J., van de Vondervoort, I. I., de Leeuw, M. J., Wijlaars, L. P., Maes, J. H., and Homberg, J. R. (2012). Serotonin transporter knockout rats show improved strategy set-shifting and reduced latent inhibition. Learn. Mem. 19, 190-193. doi: 10.1101/lm.025908.112

Nulman, I., Rovet, J., Stewart, D. E., Wolpin, J., Pace-Asciak, P., Shuhaiber, S., et al. (2002). Child development following exposure to tricyclic antidepressants or fluoxetine throughout fetal life: a prospective, controlled study. Am. J. Psychiatry 159, 1889-1895. doi: 10.1176/appi.ajp.159.11.1889

Oberlander, T., Gingrich, J., and Ansorge, M. (2009). Sustained neurobehavioral effects of exposure to SSRI antidepressants during development: molecular to clinical evidence. Clin. Pharmacol. Ther. 86, 672-677. doi: 10.1038/clpt.2009.201

Oberlander, T. F., Grunau, R. E. Fitzgerald, C., Ellwood, A. L., Misri, S., Rurak, D., et al. (2002). Prolonged prenatal psychotropic medication exposure alters neonatal acute pain response. Pediatr. Res. 51,
443-453. doi: 10.1203/00006450200204000-00008

Oberlander, T. F., Grunau, R. E., Fitzgerald, C., Papsdorf, M., Rurak, D., and Riggs, W. (2005). Pain reactivity in 2-month-old infants after prenatal and postnatal selective serotonin reuptake inhibitor medication exposure. Pediatrics 115 , 411-425. doi: 10.1542/peds.20040420

Oberlander, T. F., Papsdorf, M., Brain, U. M., Misri, S., Ross, C., and Grunau, R. E. (2010). Prenatal effects of selective serotonin reuptake inhibitor antidepressants, serotonin transporter promoter genotype (SLC6A4), and maternal mood on child behavior at 3 years of age. Arch. Pediatr. Adolesc. Med. 164, 444-451. doi: 10.1001/archpediatrics.2010.51

Olivier, J., Blom, T., Arentsen, T., and Homberg, J. (2011). The age-dependent effects of selective serotonin reuptake inhibitors in humans and rodents: a review. Prog. Neuro. Psychopharmacol. Biol. Psychiatry 35, 1400-1408. doi: 10.1016/j.pnpbp.2010.09.013

Owens, M., Goodyer, I. M., Wilkinson, P., Bhardwaj, A., Abbott, R. Croudace, T., et al. (2012). 5HTTLPR and early childhood adversities moderate cognitive and emotional processing in adolescence. PLOS ONE 7:e48482. doi: 10.1371/journal.pone.0048482

Petrides, M. (2005). Lateral prefrontal cortex: architectonic and functional organization. Philos. Trans. R. Soc. B Biol. Sci. 360, 781-795. doi: 10.1098/rstb.2005.1631

Popa, D., Léna, C., Alexandre, C., and Adrien, J. (2008). Lasting syndrome of depression produced by reduction in serotonin uptake during postnatal development: evidence from sleep, stress, and behavior. J. Neurosci. 28, 3546. doi 10.1523/JNEUROSCI.4006-07.2008

Preece, M., Dalley, J., Theobald, D., Robbins, T., and Reynolds, G. (2004). Region specific changes in forebrain 5-hydroxytryptamine la and 5-hydroxytryptamine $2 \mathrm{a}$ receptors in isolation-reared rats: an in vitro autoradiography study. Neuroscience 123, 725-732. doi: 10.1016/j.neuroscience.2003.10.008

Reuter, M., Ott, U., Vaitl, D., and Hennig, J. (2007). Impaired executive control is associated with a variation in the promoter region of the tryptophan hydroxylase 2 gene. J. Cogn. Neurosci. 19, 401-408. doi: 10.1162/jocn.2007.19.3.401

Riedel, W. J., Eikmans, K., Heldens, A., and Schmitt, J. A. J. (2005) 
Specific serotonergic reuptake inhibition impairs vigilance performance acutely and after subchronic treatment. J. Psychopharmacology 19, 12-20. doi: 10.1177/0269881105048887

Riggs, N. R., Blair, C. B., and Greenberg, M. T. (2004). Concurrent and 2-year longitudinal relations between executive function and the behavior of 1 st and 2nd grade children. Child Neuropsychol. 9, 267-276. doi: 10.1076/chin.9.4.267.23513

Risch, N., Herrell, R., Lehner, T., Liang, K., Eaves, L., Hoh, J., et al. (2009). Interaction between the serotonin transporter gene (5HTTLPR), stressful life events, and risk of depression. J. Am. Med. Assoc. 301, 2462-2471. doi: $10.1001 /$ jama.2009.878

Roiser, J. (2011). Bridging the gap between genes and behaviour: the case for neuroimaging genetics. J. Neurol. Neurosurg. Psychiatry 82, e2. doi: 10.1136/jnnp-2011-300504.24

Roiser, J. P., Blackwell, A. D., Cools, R., Clark, L., Rubinsztein, D. C., Robbins, T. W., et al. (2006). Serotonin transporter polymorphism mediates vulnerability to loss of incentive motivation following acute tryptophan depletion. Neuropsychopharmacology 31, 2264-2272. doi: 10.1038/sj.npp. 1301084

Roiser, J. P., Müller, U., Clark, L., and Sahakian, B. J. (2007). The effects of acute tryptophan depletion and serotonin transporter polymorphism on emotional processing in memory and attention. Int. J. Neuropsychopharmacol. 10, 449. doi: 10.1017/S146114570600705X

Salisbury, A. L., Ponder, K. L., Padbury, J. F., and Lester, B. M. (2009). Fetal effects of psychoactive drugs. Clin. Perinatol. 36, 595. doi: 10.1016/j.clp.2009.06.002

Sasaki-Adams, D. M., and Kelley, A. E. (2001). Serotonin-dopamine interactions in the control of conditioned reinforcement and motor behavior. Neuropsychopharmacology
25, 440-452. doi: 10.1016/S0893133X(01)00240-8

Schmitt, J. A., Kruizinga, M. J., and Riedel, W. J. (2001). Non-serotonergic pharmacological profiles and associated cognitive effects of serotonin reuptake inhibitors. J. Psychopharmacol. 15, 173-179. doi: 10.1177/026988110101500304

Schmitt, J. A. J., Jorissen, B. L., Sobczak, S., van Boxtel, M. P. J., Hogervorst, E., Deutz, N. E. P., et al. (2000). Tryptophan depletion impairs memory consolidation but improves focussed attention in healthy young volunteers. J. Psychopharmacol. 14, 21-29. doi: 10.1177/026988110001400102

Schmitt, J. A. J., Wingen, M., Ramaekers, J. G., Evers, E. A. T., and Riedel, W. J. (2006). Serotonin and human cognitive performance. Curr. Pharm. Des. 12, 2473-2486. doi: 10.2174/138161206777698909

Schonfeld, A. M., Paley, B., Frankel, F., and O'Connor, M. J. (2006). Executive functioning predicts social skills following prenatal alcohol exposure. Child Neuropsychol. 12, 439-452. doi: 10.1080/09297040600611338

Schruers, K., Esquivel, G., van Duinen, M., Wichers, M., Kenis, G., Colasanti, A., et al. (2011). Genetic moderation of $\mathrm{CO}_{2}$-induced fear by 5-HTTLPR genotype. J. Psychopharmacol. 25, 37-42. doi: $10.1177 / 0269881110372543$

Shirtcliff, E. A., and Essex, M. J. (2008). Concurrent and longitudinal associations of basal and diurnal cortisol with mental health symptoms in early adolescence. Dev. Psychobiol. 50, 690-703. doi: 10.1002/dev. 20336

Siepmann, M., Grossmann, J., MückWeymann, M., and Kirch, W. (2003). Effects of sertraline on autonomic and cognitive functions in healthy volunteers. Psychopharmacology (Berl.) 168, 293-298. doi: 10.1007/s00213-003$1448-4$

Simpson, K. L., Weaver, K. J., de VillersSidani, E., Lu, J. Y., Cai, Z., Pang,
Y., et al. (2011). Perinatal antidepressant exposure alters cortical network function in rodents. Proc. Natl. Acad. Sci. U.S.A. 108, 18465-18470. doi: 10.1073/pnas.1109353108

Strobel, A., Dreisbach, G., Müller, J., Goschke, T., Brocke, B., and Lesch, K. P. (2007). Genetic variation of serotonin function and cognitive control. J. Cogn. Neurosci. 19, 1923-1931. doi: 10.1162/jocn.2007.19.12.1923

Taghavi, M. R., Neshat-Doost, H. T., Moradi, A. R., Yule, W., and Dalgleish, T. (1999). Biases in visual attention in children and adolescents with clinical anxiety and mixed anxiety-depression. J. Abnorm. Child Psychol. 27, 215-223. doi: 10.1023/A:1021952407074

Taylor, S. E., Way, B. M., Welch, W. T., Hilmert, C. J., Lehman, B. J., and Eisenberger, N. I. (2006). Early family environment, current adversity, the serotonin transporter promoter polymorphism, and depressive symptomatology. Biol. Psychiatry 60, 671-676. doi: 10.1016/j.biopsych.2006.04.019

Valluzzi, J. A., and Chan, K. H. (2007). Effects of fluoxetine on hippocampal-dependent and hippocampal-independent learning tasks. Behav. Pharmacol. 18, 507-513. doi: 10.1097/FBP.0b013e3282ee2a91

van Ijzendoorn, M. H., Belsky, J., and Bakermans-Kranenburg, $M$. J. (2012). Serotonin transporter genotype 5HTTLPR as a marker of differential susceptibility? A meta-analysis of child and adolescent gene-by-environment studies. Transl. Psychiatry 2:e147. doi: 10.1038/tp.2012.73

Varnäs, K., Halldin, C., and Hall, H. (2004). Autoradiographic distribution of serotonin transporters and receptor subtypes in human brain. Hum. Brain Mapp. 22, 246-260. doi: 10.1002/hbm.20035

Weikum, W. M., Oberlander, T. F., Hensch, T. K., and Werker, J. F. (2012). Prenatal exposure to antidepressants and depressed maternal mood alter trajectory of infant speech perception. Proc. Natl. Acad. Sci. U.S.A. 109, 17221-17227. doi: 10.1073/pnas. 1121263109

Zanto, T. P., Rubens, M. T., Thangavel, A., and Gazzaley, A. (2011). Causal role of the prefrontal cortex in top-down modulation of visual processing and working memory. Nat. Neurosci. 14, 656-661. doi: $10.1038 / \mathrm{nn} .2773$

Zheng, J., Xu, D., Li, K., Wang, H., Shen, P., Lin, M., et al. (2011) Neonatal exposure to fluoxetine and fluvoxamine alteres spine density in mouse hippocampal CA1 pyramidal neurons. Int. J. Clin. Exp. Pathol. 4, 162 .

Conflict of Interest Statement: The authors declare that the research was conducted in the absence of any commercial or financial relationships that could be construed as a potential conflict of interest.

Received: 19 July 2013; accepted: 24 September 2013; published online: 11 October 2013.

Citation: Weikum WM, Brain U, Chau CMY, Grunau RE, Boyce WT, Diamond A and Oberlander TF (2013) Prenatal serotonin reuptake inhibitor (SRI) antidepressant exposure and serotonin transporter promoter genotype (SLC6A4) influence executive functions at 6 years of age. Front. Cell. Neurosci. 7:180. doi: 10.3389/fncel.2013.00180

This article was submitted to the journal Frontiers in Cellular Neuroscience. Copyright () 2013 Weikum, Brain, Chau, Grunau, Boyce, Diamond and Oberlander. This is an open-access article distributed under the terms of the Creative Commons Attribution License (CC BY). The use, distribution or reproduction in other forums is permitted, provided the original author(s) or licensor are credited and that the original publication in this journal is cited, in accordance with accepted academic practice. No use, distribution or reproduction is permitted which does not comply with these terms. 